\title{
Analysis and Suggestions on Chinese Industrial Tourism Development
}

\author{
Ying Jia \\ College of Economic \& Management Science, Dali University \\ Dali 671003, China \\ E-mail: jiaying0303@yahoo.com.cn
}

This research is sponsored by Doctor' scientific research start-up program of Dali University.

\begin{abstract}
The paper firstly analyzed the status quo of Chinese industrial tourism development by studying "First National Industrial and Agricultural Tourism Demonstration Sites". On this basis, suggestions were put forward for future development. The paper thought that making clear the relationship between industry and tourism, fully utilizing enterprises' distinctive resources, applying the concept of experience tourism to develop distinctive products as well as fully displaying the charm of industrial tourism should be the focus in the future industrial tourism development.
\end{abstract}

Keywords: Industrial tourism, The status quo, Suggestions, Experience tourism

\section{Introduction}

In China, a real sense of industrial tourism began to grow and cause attention in the late 1980s with the development of educational tourism market. With the adjustment of industrial structure and the vigorous development of tourism, industrial tourism has gradually become a new economic growth point of a region or an enterprise and is playing more and more important role in many aspects such as accelerating industry structure adjustment, rising famous degree of a region or an enterprise, maintaining national characteristic industry, promoting regional tourism development. Generally speaking, after about 20 years of trial and effort, industrial tourism is gradually growing up and still has broad space and good potentiality for future development in China. But due to a shorter industrialization history, relatively less industrial relic resources and lack of experience in industrial tourism development, there still exists a larger gap between China and western countries in quantity and quality of industrial products, market share, economic benefits etc. In the next part, an status quo analysis of industrial tourism development will be conducted by means of studying "First National Industrial and Agricultural Tourism Demonstration Sites".

\section{The Status Quo}

\subsection{Geographic distribution}

The geographic distribution and quantity of "First National Industrial and Agricultural Tourism Demonstration Sites" are shown in table 1.

According to statistics, at present, industrial tourism development of our country is uneven. Generally speaking, the provinces, cities or autonomous regions with traditional old industrial base, heavy industry base or highly industrialized areas have witnessed relatively more rapid development. Examples are Liaoning, Jilin, Shandong, Zhejiang, Guangdong, Beijing. Central and eastern regions and cities have undertaken better progress and results than western areas in developing industrial tourism. For example, in Shandong province, successful industrial tourism products no longer concentrates in big cities but also appears in middle and small cities. Furthermore, some world famous industrial tourism brand such as Qingdao Beer, Haier began to appear. In Beijing and Shanghai, industrial tourism is inextricably linked with urban tourism. In Northeast China, industrial tourism has become a brilliant point indicating the development and transformation of old industrial base. In eastern China where private economy is the most well-developed, industrial tourism has become private enterprises' priority in planning and construction. But in western region where modern industry is relatively weak, industrial tourism development is backward compared with central and eastern China. Guizhou, Ningxia, Yunnan Province are examples.

\subsection{Types of enterprises involved}

We can see the main types of enterprises involved in developing industrial tourism program through table 2.

According to table 2, the enterprises developing industrial tourism activities usually fall into heavy industry, high technical industry, traditional old industry or those undertaking national important engineering construction projects such as Bao Steel, Da Qing oil field, Gezhouba Project. Light industry and traditional industry 
enterprises which have closer relationship with people's daily life are weaker in developing industrial tourism projects. This reflects somewhat different ideas and concept between China and western countries in developing industrial tourism. In some western countries, industrial tourism is closely linked with protection and preservation of industrial relics, traditional industry as well as handicraft manufacturing industry. These enterprises make full use of their distinctive industrial resource to develop industrial tourism products and projects. Such kind of industrial tourism products and projects usually gains wide recognition and appreciation by tourists due to its unique cultural connotation, high degree of participation, and satisfying nostalgic need to a great extent. Chinese enterprises should absorb international advanced experience, manage to break down restrictions in thought, enlarge product variety and speed up industrial tourism development.

\subsection{Developing and marketing model}

From types of the industrial tourism products developed by the above mentioned 103 "First National Industrial and Agricultural Tourism Demonstration Sites", the developing model of products mainly falls into two kinds: single product (or special production process) developing model, and comprehensive scenic spot developing model. The former refers to the model based on a certain product or production technical process which is regarded as tourist attraction, example is a workshop belonged to brewing industry or a motorcycle assemble workshop. While the latter is such a developing model that regards the whole enterprise as a multifunction scenic area including six tourism elements. In early industrial tourism development, most enterprises adopted single product developing model. With continuous exploring and further development, more and more industrial enterprises gradually adopt comprehensive scenic spot developing model. Compared with comprehensive scenic spot developing model, single product developing model exists some problems such as sparsity of product, short stay, poor economic profits. Now, many enterprises still adopt single product (or production process) developing model supplemented by visiting factory areas and shopping, not really realizing multifunction of tourism.

\subsection{Quality of products and economic benefits}

Though more and more attention has been paid to industrial tourism, there still exist some misconceptions, as usually result in the separation of "industry" and "tourism" in actual product planning. Generally speaking, our total developing level is still low, "visiting"+"shopping" is the main developing model at present stage. In some planners' eyes, industrial tourism means advertising and promotion for the products of enterprises.

Developing industrial tourism needs the investment of human resources and capital. Nowadays, due to misconceptions and limitation of actual conditions, many industrial tourism projects are unattractive with incomplete tourist facilities and services and lack of tourists' participation. Visiting factories becomes the main activity for tourists while product promotion becomes main purpose for enterprises. For many enterprises, tourism income mostly depends on visiting tickets which is very low compared to profits from industry production. Social effect of industrial tourism can not be incarnated and tourists' satisfaction is lower.

\section{Suggestions}

\subsection{To make clear the relationship between industry and tourism, and give industrial tourism a correct positioning.}

Essentially, industrial tourism is the combination of industry and tourism. A clear recognition of the relationship between industry and tourism is the precondition for developing industrial tourism. Industry production is the basis for developing tourism activities, while promoting the development of industry production is of course one of the purpose of developing industrial tourism. In the process of developing industrial tourism, planners should take positive factors from both industry and tourism into consideration. Ideas and experience from industry production can be applied to industrial tourism development. With the development of modern industrial production, the quality and level of industrial tourism should be continuously raised. It should be emphasized that industrial tourism is not the substitute of industry production but an effective way to further promote industry production as well as create better conditions for the development of enterprises, local economy and society.

Industrial tourism is a market-oriented industry which can not go without correct market positioning. Industrial tourism should not be regarded as a simple combination of tourism and industry but a completely new industry. Since its inception, this new industry is closely related to tourists' needs. So, benefits from developing industrial tourism could only be gained by catering to tourists' needs. For enterprises, industrial production and industrial tourism should promote and support each other.

When planning production such as facilities and layout of factories, planers could take tourism functions into consideration in the mean time. That means the plan for developing industrial tourism should be taken into 
strategic plan of enterprises. New technologies, distinctive features and advantages of industry production could be turned into new attracting points for tourists. On the other hand, negative effects from industrial tourism should be eliminated or minimized. Only by this way could quality and benefits from industrial tourism be enhanced.

\subsection{To make full use of industrial resources to develop distinctive tourism product.}

Nowadays, some enterprises have not yet recognized and fully utilized their own resource advantages in developing tourism products. Apart from those large modern industrial enterprises, medium or small-sized enterprises could also develop special tourism products by fully digging and utilizing their own resources. China has long history as well as advanced civilization. National distinctive industries and traditional handicrafts have special meaning and value as medium in carrying Chinese culture. The distinctive resources of those enterprises can be fully used in developing industrial tourism products including distinctive tourism commodities and souvenirs. Tourism products based on such kind of resources are usually very attractive due to their regional characteristics and have potentials to become even world famous tourism products. Jingdezhen ceramics is one of such examples. As an up-rising manufacturing country, China has relatively fewer types of industrial heritage compared with western countries. But China has its own advantages. For example, modern industrial heritage as well as achievements of development of heavy industry in the period of early establishment of new China are special industrial tourism resources. Distinctive feature is the soul of a tourism product. Industrial tourism has its own characteristics and advantages in developing distinctive products.

For example, coal industry bases are not choices for natural tourism programs such as establishment of resorts and villas. While, coal production process or related production facilities may be best choice for industrial tourism resources. Slightly modified coal mine train and coal carvings may become attractive and welcome tourist products. But at present, due to the lack of recognition of advantages and characteristics of their own tourism resources as well as a lack of having a clear idea about market needs, many enterprises blindly imitate competitors' products. This inevitably results in homogeneity and low quality of products. Lack of recognition of resources advantages, considerable market plan as well as respective investment has become a bottleneck in industrial tourism development.

\subsection{To introduce the concept of experience tourism to show the charm of industrial tourism}

\subsubsection{To grasp the particularity of industrial tourism}

Industrial tourism is a new form of tourism having its own characteristics. When developing tourism programs, planners should highlight the characteristics of industrial tourism to let tourists fully experience the charm of industrial tourism. In industrial tourism program, enterprise including its products or production process is tourism attraction which is different from traditional aesthetic objects. "Industry" usually looks strange and mysterious with more "hard" elements in general people's eyes. Therefore, more human elements should be added in industrial tourism products to enhance its affinity when planning tourism programs. Corporate culture is an important aspect to be displayed and stressed. "Soft" culture could make industrial products closer to general tourists and give products more connotation. Another prominent feature of industry tourism is its strong intellectual and educational nature. How to make industry tourism activities play more educational role and at the same time avoid boring sermon is an important topic. Methods such as on-the-site displaying, model displaying, dynamic experience could be applied in program design. Tsingtao Brewery Company has already made dynamic film to illustrate beer production process to enhance tourists' impression and experience. In Tsingtao Beer museum especially built for tourists, workshop outlay and arrangement completely reproduce original production history and is highly appreciated by tourists. Industrial tourism has an advantage of involvement which could be used in product design to motivate tourists' interest and participation, and furthermore to enhance tourists' satisfaction. When designing activities, more attention should be paid to avoid hidden dangers from activities. So, special charm of industrial tourism could be displayed only after the feature of industrial tourism was fully grasped.

\subsubsection{To introducing the concept of experience tourism when designing programs}

Some enterprises misunderstand industrial tourism as a means of sales and promotion due to its special role in increasing profits and enhancing popularity. Industrial tourism has somewhat become tourism of advertising. Visiting production process, hearing enterprise history, purchasing products has become main contents of industrial tourism and fixed developing pattern for some enterprises. This inevitably results in tourists' dissatisfaction and disappointment. It is difficult for planners to design attractive tourism products once tourists' needs are ignored. A benefit balance should be established between tourists and enterprise. One-sided pursuit of enterprise profits could only result in poor tourism revenue. In essence, tourism is experience. For tourists, 
industrial tourism means a special experience, a kind of on-site experience. Therefore, the concept of experience could be introduced into industrial tourism program design. The essence of design of industrial tourism products is to create a special and interesting tourism experience to satisfy tourists' sensory and mental needs. A motivation---process---objective model could be used in industrial tourism planning. We put forward such a model as a new rule in the research of tourist experience and regard it as the soul of modern experience tourism. The model displays the motivation of modern tourists and their experience objectives as well as the process of realizing their objectives.

Specifically speaking, in the design of industrial tourism programs, planners should start from the characteristics of industrial tourism, and try to make the products more sensible, understandable and easier to participate in so as to enhance the tourists' experience effect. Compared with other types of tourism, space for industrial tourism activities are relatively limited. In order to create unique tourism experience in such a limited space, planners should put emphasis on creating a special atmosphere for tourists. In the visual aspect, dynamic nature of industrial tourism should be emphasized. For example, planner can put focus on displaying booming and busy scene of industrial production or highlighting mystery from high technology. Planners could also make full use of on-site sound to create special effect. Sounds from industrial enterprises can usually give people special imagination and sense of mystery. In a word, planners should pay more attention on enhancing sensory stimulation to give tourists more pleasure and excitement while designing tourism activities. At the same time, planners should take care to change contents of activities continuously in limited space to avoid dullness and try to combine visit, interactive communication and participation together to satisfy tourists' needs for gaining knowledge and self-improvement. In order to make tourism products more understandable, scientific as well as interesting methods must be used to display complex production process or technique. Dull lecture and elusive terms should be avoided in disseminating knowledge and introducing production process flow. Instead, vivid displaying methods such as model, films should be applied. Special facilities, small workshop could be provided for tourists' participation and operation which would make the tour more interesting and impressive.

\subsection{To standardize service and strengthen marketing}

In China, industrial tourism development is still at its initial stage, tourism services need to be improved a lot. At present, total service level of our country is relatively lower compared with western countries. The enterprises developing tourism activities should conduct tourism service quality inspection according to Guide Specification for Industrial Tourism Development promulgated by China National Tourism Administration. Tourism administrative institutes as well as quality service reception center should be established to provide human-oriented, personalized, fine service for tourists. Specifically, improved road signs and attractions introduction should be set up in visit areas of the factory to facilitate tourists. Security should be enhanced to eliminate hidden dangers to guarantee tourists' safety. In the aspect of marketing, planners should put more attention on analysis of target markets and try to make different marketing plans according to different needs of tourists.

\section{Summary}

Although, industrial tourism development is still at its early stage in China, its huge development potential has drawn attentions of scholars and enterprise people. With further industrial structure adjustment and vigorous development of tourism, industrial tourism will become a brilliant and amazing scenery in the chain of tourism industry of our country. In practice, industrial tourism development model with Chinese characteristics should be established on the basis on absorbing foreign advanced experiences. The key point for the development of Chinese industrial tourism is that planners should deeply understand the feature of industrial tourism, make full use of resources advantages to develop distinctive products and enhance human-oriented concept in design industrial tourism products and activities.

\section{References}

China National Tourism Administration. (2005). Complete collection of first national industrial and agricultural tourism demonstration sites. Beijing:Tourism Education Press, pp1-33.

$\mathrm{Li}$, Jie and Li, Tong Sheng. (2007).The status quo and development trend of Chinese industrial tourism. Journal of northwest university, 6, 493-496.

Li, Yue Jun. (2003). Case study of British industrial tourism attraction. Social scientist, 6,109-115.

Sun, Gen Nian. (2004). Regional development and regional co-development of tourism industry.Human geography, 4,1-5.

Tong, Yu Quan. (2006). Characteristics of urban tourism and principles of planning.Urban problem, 5,36-39. 
Wang, Xing Bin. (2000).Guidelines for tourism industry planning. Beijing:China tourism press,pp 23-48.

Wu,Xiang Li. (2002). The basic characteristics and experience of British industrial tourism development.World geography,4,73-79.

Table 1. Distribution of " First National Industrial and Agricultural Tourism Demonstration Sites”

\begin{tabular}{|c|c|c|}
\hline Order & Number & Provinces, cities, autonomous region \\
\hline 1 & 11 & Zhejiang \\
\hline 2 & 10 & Henan \\
\hline 3 & 9 & Liaoning \\
\hline 4 & 8 & Jilin \\
\hline 5 & 6 & Shandong, Guangdong, Anhui \\
\hline 6 & 5 & Hebei, Shanxi \\
\hline 7 & 4 & Jiangsu, Heilongjiang \\
\hline 8 & 3 & Sichuan, Fujian, Gansu \\
\hline 9 & 2 & Guangxi, Yunnan, Hunan, Ne Mongol, Chongqing, Beijing, Xinjiang \\
\hline 10 & 1 & Guizhou, Ningxia, Hubei, Jiangxi \\
\hline
\end{tabular}

Table 2. Types of enterprises of "First National Industrial and Agricultural Tourism Demonstration Sites"

\begin{tabular}{|c|c|c|c|}
\hline Type of enterprises & Number & Type of enterprises & Number \\
\hline Brewing Industry & 18 & Healthcare industry & 7 \\
\hline $\begin{array}{c}\text { Automobile, ship, aircraft and other vehicle } \\
\text { industry }\end{array}$ & 12 & Food and beverage industry & 6 \\
\hline Hydroelectricity & 12 & Handicrafts industry & 6 \\
\hline Petroleum, coal, mineral industry & 8 & Garment, textile industry & 4 \\
\hline Ceramic industry & 7 & daily commodity & 3 \\
\hline Steel manufacturing & 7 & Tobacco industry & 2 \\
\hline electric apparatus & 7 & others & 4 \\
\hline
\end{tabular}

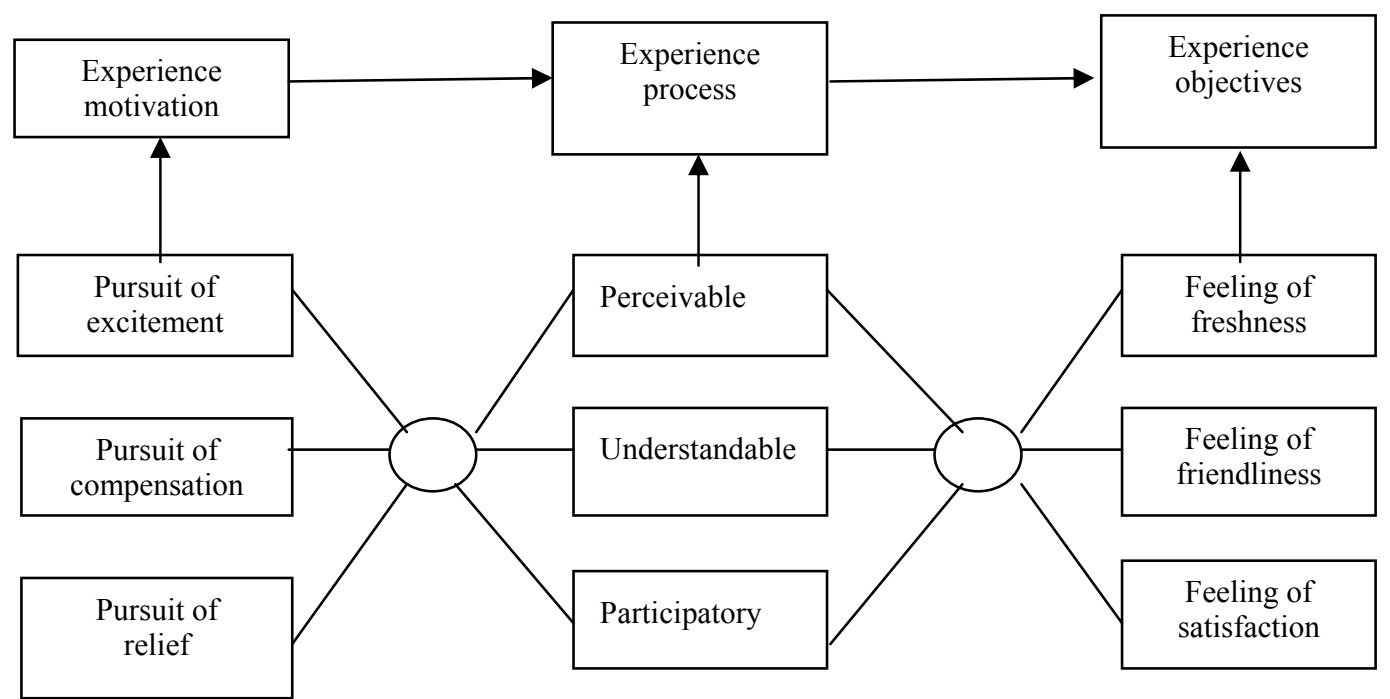

Figure 1. Motivation - Process - Objectives Model of Tourist Experience 